\title{
Introducing the Anthropocene: The human epoch
}

\author{
This article belongs to Ambio's 50th Anniversary Collection. Theme: Anthropocene
}

\author{
Will Steffen
}

Published online: 15 March 2021

\section{INTRODUCTION}

The term and concept of the Anthropocene were introduced by atmospheric chemist Paul Crutzen in 2000 at a meeting of the Scientific Committee of the IGBP (International Geosphere-Biosphere Programme) in Cuernavaca, Mexico. The Anthropocene concept had an immediate impact on the IGBP community, rapidly becoming a central organizing principle for the IGBP synthesis project (Steffen et al. 2004). However, the Anthropocene was still little known outside of the IGBP community. Two papers published in Ambio, discussed in detail below, played key roles in the development of the concept of the Anthropocene and its increasingly wide impact in the broader research community and beyond.

\section{THE ANTHROPOCENE: ARE HUMANS NOW OVERWHELMING THE GREAT FORCES OF NATURE?}

The Steffen et al. (2007) publication (hereafter SCM paper) marked the emergence of many key features of the Anthropocene concept in the peer-reviewed literature. The paper arose from a 2005 Dahlem Workshop Report on 'Sustainability or Collapse? An Integrated History and Future of People on Earth' (Costanza et al. 2006), and expanded on the outcomes of one of the working groups (Hibbard et al. 2006).

The paper brought together as co-authors Paul Crutzen, who in 2000 first introduced the 'Anthropocene' term and concept in an Earth System context (Crutzen 2000), and John McNeill, an historian who had described in his landmark book 'Something New Under the Sun' the explosion of human activity in the twentieth century and its impacts (McNeill 2001). The collaboration among authors from the geosciences and the humanities signalled the beginning of a long-term collaboration between these areas of research and scholarship, as well as heralding the importance the Anthropocene concept for all of humanity, not just the natural sciences.

The 'Great Acceleration' graphs quantifying the explosion of human activity since the mid-twentieth century (Hibbard et al. 2006) appeared in the peer-reviewed literature for the first time. They had been published, along with a companion set of graphs showing change in the structure and functioning of the Earth System, in the IGBP (International Geosphere-Biosphere Programme) synthesis book (Steffen et al. 2004), and the term 'Great Acceleration' was first used in the Dahlem workshop (Hibbard et al. 2006).

The SCM paper foreshadowed the debate on the start date for the Anthropocene, which became prominent from 2009 with the formation then of the Anthropocene Working Group to explore the Anthropocene as a potential new interval in the Geologic Time Scale (AWG 2020). The SCM paper proposed the concept of stages of the Anthropocene. We argued that the Anthropocene began with the advent of the industrial revolution around 1800, or more broadly in the 1800-1850 period (Crutzen 2002), but also emphasized the Great Acceleration as a critical point in the trajectory of the Anthropocene. Proposals for a much earlier start for the Anthropocene, around the mid-Holocene, were also noted.

SCM proposed that the first stage of the Anthropocene ended abruptly in 1945 with the beginning of the Great Acceleration. But rather bravely, we also foreshadowed an end to this second stage at 2015 , based on a potential tipping point in the relationship of humanity with the rest of the Earth System. Perhaps somewhat optimistically, we 
suggested that by 2015 the dangers of the current trajectory of the Anthropocene would become apparent and that humanity would take decisive actions to change the trajectory from one based on exploitation of the Earth System to a pathway focused on stewardship. This change in pathways would then become Stage 3 of the Anthropocene. In retrospect, this prediction was eerily accurate. The landmark Paris Climate Agreement was reached in 2015, and the United Nations Sustainable Development Goals (SDGs) were adopted also in 2015. Now in 2020, it is not yet apparent that these international agreements really constitute a global tipping point; this next decade will likely be decisive in that regard.

The SCM paper also had something to say about potential future trajectories of the Anthropocene for the rest this century and possibly beyond. We proposed three scenarios for the future were:

- Business-As-Usual-this trajectory focused on the risks of continuing on the pathway that humanity was on in 2007. In particular, we warned of locking in changes in the Earth System for many decades given the intrinsic momentum of many of its processes, and also warned of the danger of recognising these risks too late, leading to an unavoidable collapse scenario. We used the term "uncontrollable environmental change" to describe this risk. We also, as an example of this risk, noted the potential tipping point behaviour of the Greenland ice sheet, now appearing more likely as ice loss accelerates (IPCC SROCC 2019).

- Mitigation-this term refers to a transition towards sustainability, built on both technology but also on fundamental shifts in societal values and individual behaviour. However, we also noted the formidable challenges in achieving this trajectory, given the need to rapidly turn around the momentum of the Great Acceleration. Perhaps the COVID-19 crisis will be the global break point needed to change humanity's longterm trajectory.

- Geoengineering - this was already emerging as a very controversial issue in the Earth System science community, and was beginning to be taken up as a serious option in the policy world. We noted the danger that reinforcing feedbacks in the carbon cycle as the climate warms could drive the Earth System to a hotter state, and so mentioned that to avoid this, sulphate aerosol injections into the atmosphere (a type of Solar Radiation Management (SRM)) may be necessary. Even then, the intense controversy over geo-engineering approaches was evident, and so we highlighted the enormous risks, noting that the 'cure could be worse than the disease'.
The SCM paper concluded with the statement: "Whatever unfolds, the next few decades will surely be a tipping point in the evolution of the Anthropocene." I strongly suspect that by 2030 we will have a much clearer picture of what the rest of the century holds for humanity, and much of the rest of life on the planet. By then we will have crossed the fork in the road, one pathway leading to a sustainable future initiated by the landmark 2015 agreements or the other leading to collapse and chaos. Which pathway we take is not at all clear; our future hangs in the balance.

On a personal level, the SCM paper was a very important step in my career pathway. I had worked with Paul Crutzen for nearly a decade by 2007 and benefited enormously from his formidable foresight and unparalleled ability for synthesis, integration and lateral thinking. It was no surprise that he was already a Nobel Laureate. Collaborating with John McNeill opened my eyes to the wealth of insights that historians could bring to the Anthropocene narrative, insights that are arguably more important than those of the natural sciences. If humans are now driving the trajectory of the Earth System, as the concept of the Anthropocene proposes, then we had better learn much more about who we are and where we have come from.

\section{THE ANTHROPOCENE: FROM GLOBAL CHANGE TO PLANETARY STEWARDSHIP}

The basis for the 2011 article (hereafter $\mathrm{S}$ et al.) was a working paper prepared for the "3rd Nobel Laureate Symposium on Global Sustainability: Transforming the World in an Era of Global Change ", held in Stockholm in 2011. The authorship team was an impressive array of scholars that collectively represented a very broad and deep knowledge of global change-two Nobel Laureates, numerous high profile natural scientists, eminent humanities scholars, and members of the leadership team of the Anthropocene Working Group. The product of this collaboration could best be described as a 'grand synthesis' of many important concepts that were emerging at that timea synthesis that also generated new concepts and extended existing ones into new intellectual terrain.

For example, the concept of 'ecosystem services' was extended for the first time to 'Earth System goods and services', and in that way made a strong connection between the geosphere and the biosphere, which are normally studied independently. It also foreshadowed the rise of the 'anthroposphere' in Earth System thinking via the concept of services.

The concept of social-ecological systems, which by 2011 was increasingly used in studies at local and regional levels, was expanded in this paper to the social-ecological- 
geophysical system at the planetary scale. In particular, the paper put forward that "the human enterprise is now a fully coupled, interacting component of the Earth System itself". This concept was formally recognised nine years later in a review article on the origins and evolution of Earth System science itself (Steffen et al. 2020).

Two other conceptual frameworks played prominent roles in the $S$ et al. paper's narrative, particularly in relation to the discussion of global governance. One was the Planetary Boundaries framework, introduced by Johan Rockström and colleagues in 2009, which aims to provide a natural-science based framework for describing a Holocene-like state of the Earth System and the intrinsic boundaries of the Earth System that should not be transgressed if such a stable state is to be maintained (Rockström et al. 2009). The other is the polycentric governance systems approach introduced by the late Elinor Ostrom (2010), which, in the context of the S et al. paper, was proposed as a more appropriate governance system for the Anthropocene than the present governance systems that are driving us deeper towards a planetary crisis.

An underlying theme of the paper was the use of complex systems thinking as a central tool for understanding the dynamics of the Anthropocene. At the global level, this approach was a contrast to the dominant narrative at that time of the physical climate research community that approached the climate change problem in a more classic cause-effect framework, and in 2011, had not yet employed the concepts of 'global change' and the Anthropocene. In contrast, the $\mathrm{S}$ et al. paper applied complex systems approaches to the Earth System, for example via the role of biology in negative feedbacks and resilience, and the importance of concepts such as tipping points (Lenton et al. 2008), phase locking and glacial-interglacial limit cycles in Earth System dynamics (Scheffer 2009).

The $\mathrm{S}$ et al. paper also foreshadowed the potential trajectory of the Earth System through the rest of this century and beyond, and, in particular, clearly proposed that humanity is now in the driver's seat of the planetary trajectory with a new responsibility for planetary stewardship:

....is it already too late to return to a world of the Holocene that may be already lost? Is the Anthropocene a one-way trip for humanity to an uncertain future in a new, much warmer-and very differentstable state of the Earth System?

We are the first generation with widespread knowledge of how our activities influence the Earth System, and thus the first generation with the power and the responsibility to change our relationship with the planet.

The $\mathrm{S}$ et al. paper was also rich in images that exemplified its overarching themes:
- Great Acceleration graphs-these appeared in their entirety, encompassing both the human and biophysical markers of the Great Acceleration.

- Application of the 'IPAT identity' to the Great Acceleration, creating one of the most dramatic images of this phenomenon.

- A classic graph of HDI (Human Development Index) v. Global Footprint, showing the fundamental flow of our contemporary development trajectory.

- The planetary boundaries 'radar' image, now widespread in both the research and governance communities.

- Stability landscape showing a complex system being forced past a bifurcation point, now used in the context of the future trajectory of the Earth System.

This was very likely the first time that such a wide range of now-iconic figures appeared in the same paper. Finally, the paper concluded by anticipating growing instabilities and crises in the future as human pressures on the Earth System increase. For example, the increase in size and destructiveness of large-scale disturbances has already been observed in massive heatwaves and megafires. We also cautioned that geo-engineering, a form of "symptom treatment" rather than dealing with the origin of a problem, would be increasingly promoted. This caution is now being realised as we fail to deal with climate change. Finally, and rather eerily, the paper foreshadowed the escalating risks of complex, multi-scale events like pandemics and the growing risk of multiple, connected crises at the global level.

A decade on from this paper, I am left with the feeling that many of the cautions that this paper raises, building strongly on a complex system framing of the Earth System and our role in its dynamics, have fallen on deaf ears. The students are right. In 2020 we are facing an emergency situation, not only in the climate but in the Earth System as whole as well as in globalised human society. Perhaps we need a sequel to Steffen et al. $(2007,2011)$ - a paper that focuses on solutions, such as social tipping points and fundamental, rapid transformations, rather than yet another diagnosis of the problem.

\section{REFERENCES}

AWG (Anthropocene Working Group). 2020. http://quaternary. stratigraphy.org/working-groups/anthropocene/. Accessed 29 May 2020.

Costanza, R., L. Graumlich, and W. Steffen. (eds). 2006. Sustainability or collapse. An integrated history and future of people on earth. Dahlem workshop reports 96. Cambridge, MA: MIT Press.

Crutzen, P.J. 2002. Geology of mankind: The Anthropocene. Nature 415: 23. 
Crutzen, P.J., and E.F. Stoermer. 2000. The “Anthropocene." IGBP Newsletter 41: 17-18.

Hibbard, K.A., P.J. Crutzen, E.F. Lambin, D. Liverman, N.J. Mantua, J.R. McNeill, B. Messerli, and W. Steffen. 2006. Decadal interactions of humans and the environment. In Integrated history and future of people on earth. Dahlem workshop report 96, eds. R. Costanza, L. Graumlich, and W. Steffen, 341-375. Boston, MA: MIT Press.

IPCC. 2019. Summary for policymakers. In IPCC special report on the ocean and cryosphere in a changing climate, eds. H.-O. Pörtner, D.C. Roberts, V. Masson-Delmotte, P. Zhai, M. Tignor, E. Poloczanska, K. Mintenbeck, M. Nicolai, et al.

Lenton, T.M., H. Held, E. Kriegler, J.W. Hall, W. Lucht, S. Rahmstorf, and H.J. Schellnhuber. 2008. Tipping elements in the Earth's climate system. Proceedings of the National Academic of Sciences, USA 105: 1786-1793.

McNeill, J.R. 2001. Something new under the sun. New York: W.W. Norton.

Ostrom, E. 2010. Polycentric systems for coping with collective action and global environmental change. Global Environmental Change 20: 550-557.

Rockström, J., W. Steffen, K. Noone, Å. Persson, F.S.I.I.I. Chapin, E.F. Lambin, T.M. Lenton, M. Scheffer, et al. 2009. A safe operating space for humanity. Nature 461: 472-475.

Scheffer, M. 2009. Critical transitions in nature and society. Princeton: Princeton University Press.
Steffen, W., P.J. Crutzen, and J.R. McNeill. 2007. The Anthropocene: Are humans now overwhelming the great forces of Nature? Ambio 36: 614-621. https://doi.org/10.1579/00447447(2007)36[614:taahno]2.0.co;2.

Steffen, W., Å. Persson, L. Deutsch, J. Zalasiewicz, M. Williams, K. Richardson, C. Crumley, P. Crutzen, et al. 2011. The Anthropocene: From global change to planetary stewardship. Ambio 40: 739-761. https://doi.org/10.1007/s13280-011-0185-x.

Steffen, W., K. Richardson, J. Rockström, H.J. Schellnhuber, O.P. Dube, S. Dutreuil, T.M. Lenton, and J. Lubchenco. 2020. The emergence and evolution of earth system science. Nature Reviews: Earth and Environment 1: 54-63.

Steffen, W., A. Sanderson, P.D. Tyson, J. Jäger, P. Matson, B. Moore III., F. Oldfield, K. Richardson, H.-J. Schellnhuber, B.L. Turner II., and R.J. Wasson. 2004. Global change and the earth system: A planet under pressure. The IGBP book series. New York: Springer.

Publisher's Note Springer Nature remains neutral with regard to jurisdictional claims in published maps and institutional affiliations.

\section{Will Steffen $(\square)$}

Address: Fenner School of Environment and Society, College of Science, The Australian National University, Canberra, Australia. e-mail: will.steffen@anuu.edu.au 